\title{
PENGOLAHAN AIR LIMBAH DETERJEN DENGAN TAWAS
}

\author{
Nur Indah Apriyanti \\ Pendidikan Kimia FKIP UNS \\ nurindahapriyanti@gmail.com
}

\begin{abstract}
ABSTRAK
Limbah deterjen menjadi salah satu penyebab pencemaran air yang terjadi saat ini karena banyaknya rumah dan usaha laundry yang membuang limbah deterjen sisa mencuci langsung ke saluran air. Limbah deterjen mengandung ABS (Alkil Benzene Sulfonat) serta fosfat yang cukup tinggi. Bahan-bahan berbahaya tersebut menjadi penyumbang pencemaran air yang terjadi. Pencemaran air tersebut akan merusak ekosistem perairan karena deterjen mengandung bahan yang berbahaya bagi perairan. Objek penelitian ini adalah penjernihan air limbah deterjen menggunakan tawas berbentuk serbuk. Hasil dari penelitian ini adalah tawas mampu mengurangi kadar deterjen pada air limbah sehingga deterjen yang terbuang ke perairan memiliki sedikit kandungan deterjen.

Kata kunci : deterjen, bahan berbahaya, tawas, pencemaran air.
\end{abstract}

\section{PENDAHULUAN}

Limbah deterjen menjadi salah satu limbah yang banyak dibuang ke perairan. Hal ini terjadi karena banyaknya rumah yang membuang limbah deterjennya secara langsung ke saluran air yang berujung di sungai. Selain itu, banyaknya usaha laundry di kawasan sekitar kampus ataupun permukiman warga juga menyebabkan bertambahnya jumlah limbah deterjen yang dibuang ke perairan. Air limbah deterjen tersebut mengandung bahan-bahan berbahaya yang dapat mengganggu ekosistem perairan. Natrium Dodecyl Benzen Sulfonat (NaDBS) dan Sodium Tripolyphospat (STPP) yang menjadi bahan utama penyusun deterjen tersebut sulit untuk didegradasi secara alami. Senyawa fosfat tersebut akan menyebabkan proses eutrofikasi, yaitu pencemaran air yang disebabkan adanya nutrisi berlebihan pada ekosistem perairan sehingga tanaman air menjadi subur dan menutup permukaan air. Tertutupnya permukaan air tersebut dapat menghalangi cahaya matahari untuk masuk ke dalam air sehingga binatang-binatang di air tersebut akan mati. Tawas yang biasa dijual di pasar ataupun toko memiliki berbagai manfaat, salah satunya sebagai penjernih air. 
Selain itu harganya juga terjangkau. Oleh karena itu, tawas saya pilih sebagai zat penjernih air limbah deterjen ini.

\section{METODE PENELITIAN}

Metode penelitian yang digunakan ialah pendekatan kualitatif. Metode penelitian kualitatif adalah sebuah metode riset yang bersifat deskriptif dan menggunakan analisis yang mengacu pada data, serta memanfaatkan teori yang ada sebagai pendukung.

Selain itu, penelitian ini juga menggunakan metode penelitian eksperimen dengan melakukan percobaan menambahkan tawas ke dalam air limbah deterjen. Tawas yang digunakan adalah tawas yang berbentuk serbuk. Tawas dilarutkan ke dalam 1 liter air limbah deterjen dengan konsentrasi tawas sebanyak 25 ppm, 50 ppm, 75 ppm, dan 100 ppm. Kemudian diaduk selama kurang lebih 15 menit hingga larut. Lalu didiamkan hingga terbentuk endapan dan disaring untuk memisahkan endapan dengan air menggunakan kertas saring.

Alat dan bahan yang digunakan pada percobaan penurunan kadar deterjen pada air limbah deterjen antara lain sebagai berikut.

1. Gelas beker

2. Pengaduk kaca

3. Serbuk tawas

4. Sampel air limbah deterjen

5. Kertas saring

6. Stopwatch

\section{HASIL DAN PEMBAHASAN}

Air limbah deterjen mengandung bahan-bahan kimia berbahaya yang dapat merusak ekosistem perairan. Umumnya jenis deterjen yang digunakan ialah deterjen yang mengandung ABS (Alkil Benzene Sulfonat) yang tergolong deterjen bersifat keras. Selain ABS, dalam air deterjen juga terkandung fosfat yang dapat menyebabkan eutrofikasi pada ekosistem perairan. Eutrofikasi menyebabkan 
semakin suburnya tumbuhan air salah satunya alga. Jika tumbuhan air tersebut menutupi permukaan air, maka cahaya matahari sulit untuk masuk ke dalam perairan yang berakibat pada kurangnya kadar oksigen dalam air.

Selain merusak ekosistem perairan karena air limbah tersebut mengalir ke sungai, air limbah deterjen tersebut juga mengganggu keseimbangan $\mathrm{pH}$ tanah. Kualitas air tanah menjadi semakin menurun akibat tercampur dengan kandungan limbah deterjen yang terserap. Air tanah yang kualitasnya rendah tentu tidak baik untuk dikonsumsi sehari-hari oleh masyarakat. Penanganan limbah sebelum dibuang sangat diperlukan agar tidak merusak lingkungan dan merugikan masyarakat. Salah satu penanganan limbah yang dapat dilakukan adalah dengan menurunkan kadar deterjen pada air limbah tersebut. Terdapat bahan-bahan yang dapat digunakan untuk menjernihkan air seperti tawas, kaporit, dan sebagainya.

Tawas atau Aluminium Sulfat $\left(\mathrm{Al}_{2}\left(\mathrm{SO}_{4}\right)_{3}\right)$ merupakan koagulan yang akan mengendapkan partikel koloid yang ada dalam air. Ketika dalam air, tawas akan terurai menjadi dispersi koloid yang bermuatan positif dan akan mengikat partikel koloid bermuatan negatif. Dalam penjernihan air limbah deterjen ini, ion $\mathrm{Al}^{3+}$ pada tawas akan mengikat dan mengendapkan fosfat. Sebagai koagulan alum sulfat, tawas sangat efektif untuk mengendapkan partikel koloid dan suspensi pada air maupun limbah.

Tabel 1. Pengaruh jumlah penambahan tawas terhadap kadar deterjen

\begin{tabular}{|c|c|}
\hline Jumlah Tawas (ppm) & Kadar Deterjen \\
\hline 0 & 0,62 \\
\hline 25 & 0,60 \\
\hline 50 & 0,58 \\
\hline 75 & 0,59 \\
\hline 100 & 0,58 \\
\hline
\end{tabular}




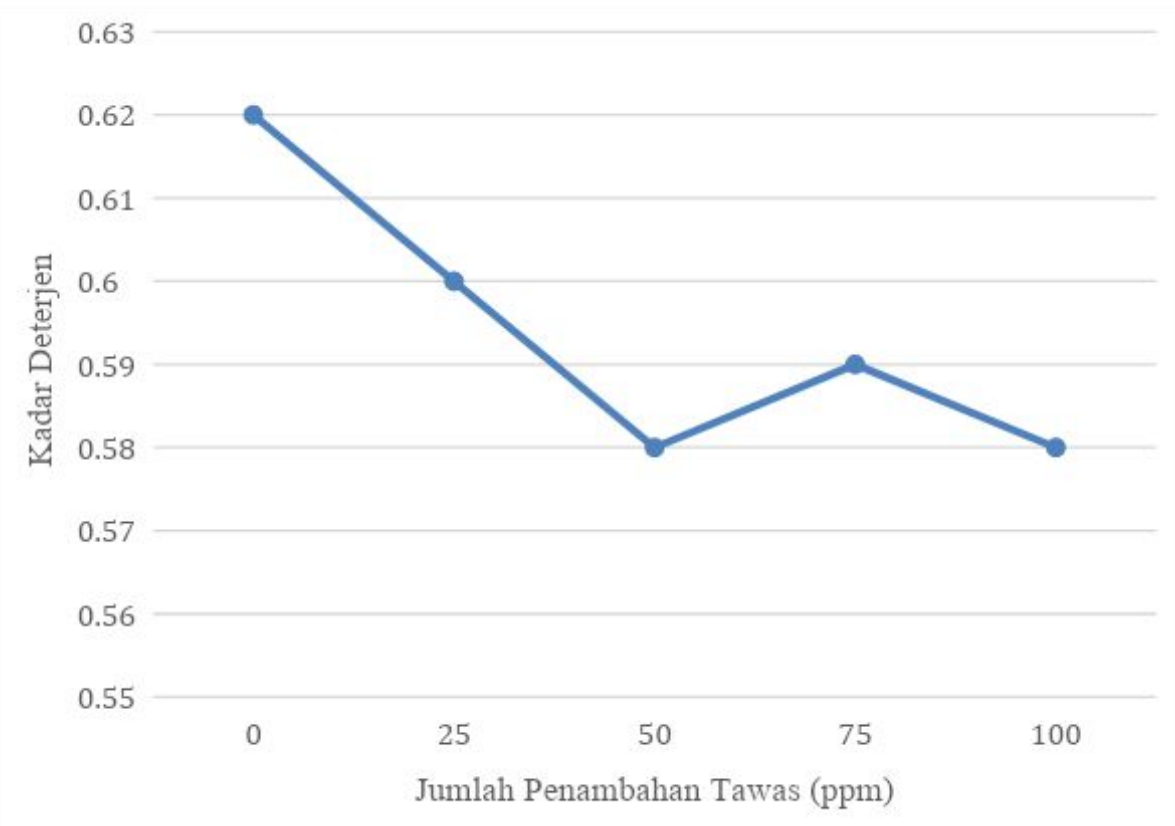

Gambar 1. Pengaruh jumlah penambahan tawas terhadap kadar deterjen

Penambahan tawas pada air limbah deterjen akan mengurangi kadar deterjen. Tawas mengendapkan partikel-partikel koloid pada air deterjen sehingga kadar deterjen pada air yang telah disaring lebih sedikit. Cara pengolahan limbah deterjen ini sangat mudah diterapkan dalam kehidupan sehari-hari khususnya bagi para ibu rumah tangga dan pengusaha jasa laundry pakaian yang sering membuang air deterjen bekas mencuci pakaian. Sebelum air deterjen bekas mencuci dibuang ke saluran air, kita dapat menambahkan serbuk tawas agar partikel koloid pada deterjen mengendap sehingga yang dibuang ke saluran air hanya air yang telah terpisah dari endapannya. Dengan demikian, pencemaran air akibat limbah deterjen dapat dikurangi dan ekosistem perairan akan terjaga.

\section{KESIMPULAN}

Pencemaran air akibat limbah deterjen bekas mencuci dapat dikurangi dengan melakukan pengolahan limbah sebelum membuangnya ke saluran air. Salah satu cara sederhana untuk mengolahnya adalah dengan menambahkan serbuk tawas pada air deterjen bekas mencuci pakaian. Tawas akan mengendapkan partikel-partikel pada deterjen sehingga air yang terpisah dari 
endapan tersebut memiliki kadar deterjen sedikit. Dengan demikian, pencemaran air dapat dikurangi dan ekosistem perairan akan terjaga.

\section{DAFTAR PUSTAKA}

Aziz, T., Pratiwi, D. Y., \& Rethiana, L. (2013). Pengaruh Penambahan Tawas $\mathrm{Al}_{2}\left(\mathrm{SO}_{4}\right)_{3}$ dan Kaporit $\mathrm{Ca}(\mathrm{OCl})_{2}$ Terhadap Karakteristik Fisik dan Kimia Air Sungai Lambidaro. Jurnal Teknik Kimia 19 (3), 56, 64.

Haderiah., Utami, Novi, D. (2015). Meminimalisir Kadar Detergen dengan Penambahan Koagulan dan Filtrasi Media Saring pada Limbah Kamar Mandi. Higiene 1 (1), 33-34.

Suastuti, D. A., Suarso, I. W., \& Putra, D. K. (2015). Pengolahan Larutan Deterjen Dengan Biofilter Tanaman Kangkungan (Ipomoea Crassicaulis) Dalam Sistem Batch (Curah) Teraerasi. Jurnal Kimia 9 (1), 98-99.

Tawas. (Online). https://id.m.wikipedia.org/wiki/Tawas (8 Desember 2019). 